\title{
Soot Formation and Oxidation in Fires from Laminar Smoke Point Measurements
}

\author{
TAREK BEJI, JIANPING ZHANG and MICHAEL DELICHATSIOS \\ The Institute for Fire Safety Engineering Research and Technology (FireSERT), University of \\ Ulster, Newtownabbey, BT37 0QB, Northern Ireland.
}

\begin{abstract}
A soot formation and oxidation model appropriate for fires is first developed for laminar axisymmetric nonpremixed flames. This model relies on flow similarity relationships to describe the structure of the flame and relate it to soot processes in laminar smoke point flames. The selection of the parameters is focused on the stoichiometric and visible heights. The evaluation of this model is achieved by means of comparisons of numerical results with experimental data and observations for an axisymmetric coflow laminar ethylene/air nonpremixed flame. The model gives satisfactory results and a good phenomenological explanation of the influence of soot processes on the structure of the flame. This model will be applied next to turbulent flames and fires.
\end{abstract}

KEYWORDS: non-premixed flames, fires, laminar smoke point, soot formation, soot oxidation.

\section{NOMENCLATURE LISTING}

\begin{tabular}{|c|c|c|c|}
\hline$A$ & Pre-exponential factor & $\gamma$ & Temperature exponent \\
\hline$C$ & Constant related to the flow rate (m) & $\xi$ & Mixture fraction \\
\hline $\mathrm{C} / \mathrm{O}$ & $\begin{array}{l}\text { Number of carbon to oxygen atoms } \\
\text { ratio }\end{array}$ & $\rho$ & Density $\left(\mathrm{kg} \cdot \mathrm{m}^{-3}\right)$ \\
\hline$E$ & $\begin{array}{l}\text { Activation energy for soot inception } \\
\left(\mathrm{J}_{\mathrm{mol}}^{-1}\right)\end{array}$ & $\tau$ & Time (s) \\
\hline$f_{v}$ & Soot volume fraction & $\chi_{r}$ & Radiative fraction \\
\hline$g$ & Acceleration of gravity $\left(9.81 \mathrm{~m} . \mathrm{s}^{-2}\right)$ & $\dot{\omega}$ & Reaction rate $\left(\mathrm{kg} . \mathrm{s}^{-1}\right)$ \\
\hline$H$ & Height (m) & $\kappa$ & Absorption coefficient $\left(\mathrm{m}^{-1}\right)$ \\
\hline$I$ & Radiation intensity (W. $\left.\mathrm{m}^{-2} \cdot \mathrm{sr}^{-1}\right)$ & \multicolumn{2}{|c|}{ Subscripts } \\
\hline$I_{b}$ & Planck function $\left(\mathrm{W} \cdot \mathrm{m}^{-2} \cdot \mathrm{sr}^{-1}\right)$ & 0 & Ambient air \\
\hline$L$ & Height (m) & $a d$ & Adiabatic \\
\hline$n$ & Particulate number density $\left(\mathrm{m}^{-3}\right)$ & $f$ & Formation \\
\hline$q_{r}$ & Radiation term (W.m²) & FT & Fuel (at the inlet) \\
\hline$R$ & $\begin{array}{l}\text { Universal gas constant } \\
\left(8.314 \mathrm{~J} \cdot \mathrm{K}^{-1} \cdot \mathrm{mol}^{-1}\right)\end{array}$ & gas & gas \\
\hline$S$ & Mass air to fuel ratio & incep. & Soot inception \\
\hline$T$ & Temperature (K) & $\max$ & Maximum \\
\hline$U$ & Integrated radiation intensity $\left(\mathrm{W} . \mathrm{m}^{-2}\right)$ & $o x$ & Oxidation \\
\hline$u_{C}$ & Centreline velocity (m/s) & $s$ & Soot \\
\hline$Y$ & Mass fraction & Smoke & Smoke emitted (end of oxidation) \\
\hline$z$ & Axial coordinate (m) & st & Stoichiometry \\
\hline Greek & & $V H$ & Visible Height \\
\hline$\alpha$ & Constant (no dimension) & \multicolumn{2}{|c|}{ Superscripts } \\
\hline$\beta$ & Dimensionless maximum temperature & ()$^{\prime \prime \prime}$ & Volumetric reaction rate \\
\hline$\Omega$ & Solid angle (sr) & ()$^{\prime \prime}$ & Reaction rate per unit surface \\
\hline
\end{tabular}




\section{INTRODUCTION}

Continuing experimental and analytical studies are carried out on soot, seeking a better understanding of its formation and burnout. It is one of the most relevant species that need to be controlled to contain fire hazards or design combustion devices, such as diesel engines. Soot has been shown to be the prevailing species in radiation, which is the dominant heat transfer in fires. Besides, these carbonaceous particles are involved in the formation of fire toxicants, e.g.: carbon monoxide. Kennedy [1] provided an excellent review describing several soot models: empirical, semi-empirical and detailed models. Despite the considerable effort deployed in soot modelling, several challenges still remain, which concern not only soot processes and kinetics but also interactions with radiation and turbulence. The model discussed in this paper lies within the class of semi-empirical models, with the intent of proposing a simplified but reliable model highly important from an engineering prospect. However, as pointed out in [1], semi-empirical models are usually calibrated via " $a d$ hoc" adjustments to achieve reasonable agreement with experimental data [2-4]. Therefore, the development of a soot model is desirable to: (i) minimize these calibrations and (ii) apply the model not only to hydrocarbons, but to a wide variety of fuels in fires. In this paper, a more extensive analysis on the soot formation model developed by Delichatsios [5] is carried out and a soot oxidation model is proposed. The aim of this work is to by-pass the detailed chemistry (computationally very expensive) by incorporating experimental measurements into a semi-empirical model, more appropriate for engineering purposes especially in fires. This model relates the soot mapping in a laminar non-premixed flame to the flame structure in terms of height, temperature, mixture fraction, density and velocity. Also, unlike most of other soot models, in this work, soot processes are assumed to be independent of the surface area, which is consistent with observations in laminar smoke point flames [3,5].

\section{FLAME HEIGHTS AND SOOT MODELLING}

The study of laminar buoyant non-premixed flames is a fundamental first step to understand the combustion process, particularly in fires. That is why these flames still receive a great attention in the combustion community. Several aspects of the flame structure have been studied. These aspects are related to the effects of pressure (correlated to the diffusion process), gravity and dilution. In this paper, we emphasise on a particular parameter, the flame height, due to its relevance in the study of soot. Burke and Shumann [6] have conducted the first extensive study on the so-called "candle-like" flames. They have made a clear distinction between the stoichiometrical ("actual") height and the "luminous" height due to soot incandescence. Roper and Smith [7] have also pointed out the importance of distinguishing between the two heights. Experimentally, Sunderland et al. [8] have noticed the difficulty of measuring the stoichiometric flame height for soot-containing flames. Regarding the processes of soot formation and oxidation other heights have been defined and studied in literature. Kumfer et al. [9] and earlier Du et al. [10] studied the soot inception mechanism in nonpremixed propane coflow flames through the concept of sooting limit. The analysis conducted in [9] led to the conclusion that there is a critical ratio C/O (related to the mixture fraction, [11]) that initiates soot inception. According to Roper and Smith [7], the soot-forming zone is delimited at a particular height $\left(H_{\max }\right)$ where soot concentration reaches a maximum; formation stops and oxidation begins. This height is different from the other heights defined previously. The same authors define an additional height $\left(H_{\text {smoke }}\right)$ to describe the end of soot oxidation.

In the light of what has been discussed above and in order to draw a clear picture of the soot mapping in the flame, three heights are retained: (i) the sooting limit, $L_{\text {incep }}$, (to by-pass the quantification of soot precursors [12]), (ii) the stoichiometric (diffusion) height, $L_{s t}$, and (iii) the visible (luminous) height, $L_{V H}$. The main assumptions made here are: (i) the maximum soot concentration occurs at stoichiometry where oxidation starts, and, (ii) soot oxidation ends at the flame visible height. This perspective is all the more interesting considering the applicability of the experimental procedure for real fuels in fires, for which chemistry is unknown.

\section{SOOT MODEL}

The approach used in this work on soot modelling, strongly relies on the structure of the flame, i.e. shape (mainly in terms of heights), temperature field, velocity field and the mixture fraction field. The last parameter is the key parameter (assuming equal diffusivities) in studying non-premixed flames since it describes the local mixing between the fuel and the oxidizer (the air). The mixture fraction gives the ratio 
of the number of carbon atoms at any location to that at the fuel supply. Thus, by assuming that there are no carbon atoms in the air, the mixture fraction takes the value of 1 on the fuel side and 0 on the air side. The stoichiometric mixture fraction is related to the net flux of the oxidizer that reacts with the fuel flux, $S$, as:

$$
\xi_{s t}=\frac{1}{S+1}
$$

Once a description of the flame structure is made, a phenomenological model is derived for the processes of soot formation and oxidation.

\section{Flame studied and its structure}

In this section some theoretical assumptions and flow similarity relationships are discussed to assess the soot formation and oxidation models. These relationships are compared against a numerical simulation of the flame in the Computational Fluid Dynamics (CFD) code, Fire Dynamics Simulator [13] in its DNS mode. The choice of this flow field solver has been motivated by its flexibility regarding the implementation and evaluation of new sub-models. Besides, FDS is a CFD code designed primarily for fire applications [13]. The simulated flame is an axisymmetric coflow laminar ethylene/air nonpremixed flame below the smoke point. The burner diameter is $1.1 \mathrm{~cm}$ and the heat release rate prescribed is $212 \mathrm{~W}$. Also, a coflowing air has been set at the velocity of $0.087 \mathrm{~m} / \mathrm{s}$. The experimental data for soot volume fraction [14] corresponding to the same numerical case is used in this paper for validation purposes. First we discuss simplified similarity relations for the laminar flame before we present detailed numerical calculations using the DNS mode in FDS.

\section{a) Temperature dependence:}

The temperature, $T$, dependence on the mixture fraction, $\xi$, in both formation and oxidation regions is taken as linear with respect to the Schvab-Zeldovich type diagram [5], assuming equal diffusivities and constant specific heat.

- In the formation region:

$\frac{T_{\max }-T}{T_{\max }-T_{0}}=\frac{\xi-\xi_{s t}}{1-\xi_{s t}} \quad ; \quad \xi_{s t}<\xi<1$

- In the soot oxidation region:

$\frac{T-T_{0}}{T_{\max }-T_{0}}=\frac{\xi}{\xi_{s t}} \quad ; \quad \xi_{V H}<\xi<\xi_{s t}$

$\xi_{V H}$ is the mixture fraction at the visible height, $T_{0}$ is the ambient temperature and $T_{\max }$ is the maximum temperature. Note that $T_{\max }$ is lower than the adiabatic temperature (e.g. $T_{a d}=2371 \mathrm{~K}$ for ethylene [10]) due to radiation heat losses. Temperature, $T$, is related to density, $\rho$, through Eq. 3.

$\rho T=\rho_{0} T_{0}$

where the subscript 0 expresses the ambient conditions.

b) Centreline velocity:

The centreline velocity, $u_{c}$, could be expressed as following:

- In the formation region:

$u_{c}=\alpha(g z)^{1 / 2}$

where $\alpha$ is a constant and $g$ is the gravitational acceleration.

- In the oxidation region, the flow is not accelerated any more after combustion has ceased at stoichiometry.

$u_{c}=\alpha\left(g L_{s t}\right)^{1 / 2}$ 
c) Mixture fraction dependence on the height along the axis

$\xi=\frac{C}{z}$

where $\mathrm{C}$ is a constant related to the flow rate.

Equation $5 \mathrm{~b}$ relates therefore the three heights used in this model to their respective corresponding mixture fractions.

$L_{\text {incep. }} \xi_{\text {incep. }}=L_{s t} \xi_{s t}=L_{V H} \xi_{V H}=C$

\section{Soot formation model}

In this section, a brief description of the model developed by Delichatsios [5] is given. Unlike major species involved in combustion, it is not possible to obtain a state relationship for soot by correlating its concentration to solely the mixture fraction. This is due to the slow reaction time of soot and its diffusion rate, different from molecular species. Therefore, the attempt made by Delichatsios [5] and explored in this work, is to relate the soot formation rate, $\dot{\omega}_{s, f}^{\prime \prime \prime}$, not only to the mixture fraction but also to the other parameters of the flame structure, density and temperature, and to the fuel concentration at the supply stream, $Y_{F T}$, (see Eq. 6).

$\dot{\omega}_{s, f}^{\prime \prime \prime}=A \rho^{2}\left(Y_{F T} \frac{\xi-\xi_{s t}}{1-\xi_{s t}}\right) T^{\gamma} e^{-E / R T} \quad\left(\mathrm{~kg} \cdot \mathrm{m}^{-3} \cdot \mathrm{s}^{-1}\right)$

where $A$ is a pre-exponential factor and $E$ is the activation energy for soot inception. Note that there is an additional temperature exponent, $\gamma$, in comparison to the original formulation for the axis of the flame [5] to account for the temperature dependence. This adjustment allows the prediction of the soot concentration peak in the wings (not in the centreline), which is in accordance with the available experimental data.

In the formation region $\left(0<z<L_{s t}\right)$, the conservation equation for soot in the centreline of an axisymmetric flame is the following:

$\rho u_{c} \frac{\partial Y_{s}}{\partial z}=\dot{\omega}_{s, f}^{\prime \prime} \quad ; \xi_{s t}<\xi<1$

where $Y_{s}$ is soot concentration.

Assuming that the maximum soot concentration occurs at stoichiometry, Eq. 7 yields:

$\left(Y_{s}\right)_{\max }=\int_{0}^{L_{s t}} \frac{\dot{\omega}_{s, f}^{\prime \prime \prime}}{\rho u_{c}} d z$

Using the theoretical simplified relations for the mixture fraction and the velocity discussed above, Eq. 8 becomes:

$\left(Y_{s}\right)_{\max }=\frac{L_{s t}}{\alpha\left(g L_{s t}\right)^{1 / 2}} \frac{1}{\tau_{s, f}}$

where

$\tau_{s, f}^{-1}=\int_{\xi_{s t}}^{l} \frac{A}{\xi}\left(\frac{\xi_{s t}}{\xi}\right)^{1 / 2} \rho T^{\gamma}\left(Y_{F T} \frac{\xi-\xi_{s t}}{1-\xi_{s t}}\right) e^{-E / R T} d \xi$

is the inverse of a soot formation time. 
Preliminary results showed an overestimation of soot concentration at the lower part of the flame (the fuel rich region). This is due to the fact that the model does not differentiate between soot and PAHs that are generally believed to be precursors to soot particles. From the experimental point of view, Liu et al. [15] pointed out the fact that the laser intensity attenuation technique may overestimate the soot concentration in the lower part of the flame since it cannot differentiate soot from PAH. Subsequently, in the soot formation model described in this work, soot formation was set to start not from the nozzle exit where the mixture fraction is $l$ (as implied by Eq. 7) but from a given value of the mixture fraction, $\xi_{\text {incep }}$. The value of $\xi_{\text {incep }}$ has not been chosen exclusively by numerical "calibration". Physically speaking, this value corresponds to the critical mixture fraction or the corresponding critical C/O ratio $[9,11]$ at which soot starts appearing in the flame. Therefore, the selection of this value for other cases (e.g. other fuels including diluted fuels) might be guided by using the sooting limit [9] and the flow similarity relationship in Eqs. 5a and 5b. Besides, this parameter might be replaced by a temperature threshold for soot inception.

\section{Soot oxidation model}

In order to have a complete soot model, soot oxidation must be incorporated. In fact, it is the competition between the two processes of formation and oxidation that is responsible for the emission of soot convected through the flame. After its inception, soot coagulates into agglomerates that are attacked by oxygen, $\mathrm{O}_{2}$, and/or hydroxyl radical, OH. In most studies, soot oxidation has been modelled as a surface-area dependant mechanism. In such models, soot surface is generally evaluated using the soot particulate number density and soot volume fraction, assuming a spherical shape of soot particulates [2]. Other surface related effects have also been studied, such as particle aging and changes in the number of active sites on soot particles. The specific oxidation rate per unit surface is evaluated by means of well-known correlations. The two main oxygen oxidation models are the model of Nagle and Strickland-Constable [16] and the model of Lee et al [17]. The oxidation rate is given as a function of the temperature and the partial pressure of oxygen. Fenimore and Jones [18] proposed a similar model based on the $\mathrm{OH}$ oxidation and used collision efficiency for $\mathrm{OH}$.

In this paper, similarly to Lautenberger et al. [3], oxidation is assumed to be diffusion controlled mechanism. However, in this work, further simplification was made by assuming a constant volumetric oxidation rate. Although such an assumption may seem contestable, it does not fully disagree with previous oxidation models, e.g. the oxidation model in Moss's Model [2]. In this model [2] the volumetric oxidation rate is given as following:

$\dot{\omega}_{s, o x}^{\prime \prime \prime}=\left(\frac{36 \pi}{\rho_{s}^{2}}\right)^{1 / 3} n^{1 / 3}\left(\rho Y_{s}\right)^{2 / 3} \dot{\omega}_{s, o x}^{\prime \prime} \quad\left(k g \cdot m^{-3} \cdot s^{-1}\right)$

where $n$ is the particulate number density $\left(\mathrm{m}^{-3}\right), \rho_{s}$ is soot density $\left(1850 \mathrm{~kg} \cdot \mathrm{m}^{-3}\right), Y_{s}$ is soot mass fraction and $\dot{\omega}_{s, o x}^{\prime \prime}$ is a specific oxidation rate per unit surface $\left(\mathrm{kg} \cdot \mathrm{m}^{-2} \cdot \mathrm{s}^{-1}\right)$.

It is important to note some interesting observations and assumptions: (a) Moss et al. [2] stated that the specific oxidation rate per unit surface increases when the mixture fraction decreases; (b) in the oxidation region, soot mass fraction decreases with the mixture fraction until complete depletion at the visible height of a non-smoking flame; (c) the number density is observed to "saturate" as a consequence of a balance between nucleation and coagulation. It is subsequently assumed to be constant in the oxidation region. Statements (a), (b) and (c) when taken in conjunction may therefore assess the legitimacy of a presumed constant volumetric oxidation rate. It is true that oxidation rates will decrease as the local temperatures decrease until oxidation ceases at about 1300K [19]. Only the latter restriction is used in the current model where oxidation rates are assumed constant in the oxidation regime along the axis of the laminar flame.

The purpose now is to quantify this presumed constant oxidation rate, $\dot{\omega}_{s, o x}^{\prime \prime \prime}$. In the oxidation region $\left(L_{s t}<\right.$ $\left.z<L_{V H}\right)$, the conservation equation for soot in the centreline of an axisymmetric flame is the following:

$\rho u_{c} \frac{\partial Y_{s}}{\partial z}=\dot{\omega}_{s, o x}^{\prime \prime \prime} \quad ; \xi_{V H}<\xi<\xi_{s t}$ 
Assuming that the maximum soot concentration that occurs at stoichiometry is fully oxidized at the visible height of the flame, Eq. 11 yields:

$$
\left(Y_{s}\right)_{\max }=\int_{L_{s t}}^{L_{V H}} \frac{\dot{\omega}_{s, o x}^{\prime \prime \prime}}{\rho u_{c}} d z
$$

Using the theoretical assumptions for the mixture fraction and the velocity discussed above, Eq. 12 becomes:

$$
\left(Y_{s}\right)_{\max }=\frac{C}{\alpha\left(g L_{s t}\right)^{1 / 2}} \int_{\xi_{V H}}^{\xi_{s t}} \frac{\dot{\omega}_{s, o x}^{\prime \prime \prime}}{\rho \xi^{2}} d \xi
$$

By using the assumptions for the temperature, density and mixture fraction (Eqs. $2 \mathrm{~b}$ and 3 ) and bearing in mind that the soot oxidation rate is constant, one obtains:

$$
\int_{\xi_{V H}}^{\xi_{s t}} \frac{\dot{\omega}_{s, o x}^{\prime \prime \prime}}{\rho \xi^{2}} d \xi=\frac{\dot{\omega}_{s, o x}^{\prime \prime \prime}}{\xi_{s t} \cdot \rho_{0}}\left[\beta \cdot \ln \left(\frac{L_{V H}}{L_{s t}}\right)+\left(\frac{L_{V H}}{L_{s t}}-1\right)\right] \quad ; \quad \beta=\left(\frac{T_{\max }-T_{0}}{T_{0}}\right)
$$

Finally, $\dot{\omega}_{s, o x}^{\prime \prime \prime}$ is estimated as following:

$$
\dot{\omega}_{s, o x}^{\prime \prime \prime}=\frac{\rho_{0} \alpha\left(g L_{s t}\right)^{1 / 2}\left(Y_{s}\right)_{\max }}{L_{s t}\left[\beta \cdot \ln \left(\frac{L_{V H}}{L_{s t}}\right)+\left(\frac{L_{V H}}{L_{s t}}-1\right)\right]} \quad\left(\mathrm{kg} \cdot \mathrm{m}^{-3} \cdot \mathrm{s}^{-1}\right)
$$

Equation 16 confirms that while approaching the laminar smoke point, which means that soot maximum concentration is increasing, if the oxidation rate is kept constant, the ratio $L_{V H} / L_{s t}$ must increase to compensate for the surplus of soot produced and to have a non-smoking flame.

If we define a soot oxidation time:

$$
\tau_{s, o x}=\frac{\rho_{0}}{\dot{\omega}_{s, o x}^{\prime \prime \prime}}
$$

Equation 16 may be rearranged using Eqs. 15 and 9a as:

$$
\beta \cdot \ln \left(\frac{L_{V H}}{L_{s t}}\right)+\left(\frac{L_{V H}}{L_{s t}}-1\right)=\frac{\tau_{s, o x}}{\tau_{s, f}}
$$

Eq.17 implies that the ratio of the visible to stoichiometric flame height is constant for all non-sooting flames because the soot oxidation time (and the soot formation time) is assumed independent of temperature. This behaviour is consistent with the similarity behaviour of non-sooting laminar flames. However, in reality [20], this ratio increases slightly as the flame height increases because the temperatures in the oxidation regime decrease (due to higher radiation losses) and thus, the oxidation time will increase (more than the soot formation time) until oxidation stops at about $1300 \mathrm{~K}$.

The transition from a non-smoking to a smoking flame is due to the freezing of soot oxidation because of a temperature drop below a threshold value about $1300 \mathrm{~K}$ [19]. Therefore, a critical value must be included to ensure the possibility of occurrence of soot burnout regarding the temperature. However, as the temperature in the oxidation region is controlled by the radiative heat loss of the soot formed, a special attention to the treatment of radiation is needed.

\section{RADIATION MODEL}

Radiative heat transfer plays a crucial role in the processes of soot formation and oxidation. In fact, the local radiative loss/gain strongly influences soot formation [21,22]. An underestimation of radiative heat 
losses leads to an overestimation of the temperature and subsequently an overestimation of soot concentration. In this work, radiation is treated by two methods:

1. A prescribed radiative fraction,

2. A modified absorption coefficient to account for the soot radiant loss in the energy equation.

\section{Prescribed radiative fraction}

The difficulty of radiation calculation, which is highly dominated by soot, is lessened by prescribing a radiative fraction, $\chi_{r}$, that defines the minimum local fraction of energy emitted as thermal radiation. The radiative fraction is a fuel-dependant parameter [13] taken as 0.2 for ethylene as it suggested in FDS database. By prescribing such a parameter, the flame structure (mainly in terms of temperature and mixture fraction) does not depend on the soot formed. This simple assumption allows a first evaluation of the model and an estimation of the value of the pre-exponential factor, $A$. This model will be referred to as Case1.

\section{Modified absorption coefficient}

In the thermal radiation model of FDS [13], the radiative loss term in the energy equation is:

$$
-\nabla \cdot q_{r}=\kappa\left(U-4 \pi I_{b}\right) \quad ; \quad U=\int_{4 \pi} I d \Omega
$$

where $\kappa$ is the absorption coefficient and $U$ is the integrated radiation intensity, $I$, over the solid angle, $\Omega$. $I_{b}$ is the Planck function.

The absorption coefficient, $\kappa$, is the sum of the contributions of gaseous species, $\kappa_{\text {gas }}$, and soot, $\kappa_{s}$ (see Eq. 19).

$$
\kappa=\kappa_{\text {gas }}+\kappa_{s}
$$

Gas absorption coefficients are tabulated as a function of mixture fraction and temperature. The soot absorption coefficient is generally correlated to the soot volume fraction, $f_{v}$, and the temperature, $T$, as:

$$
\kappa_{s}=C_{\kappa, s} f_{v} T
$$

where $C_{\kappa, S}$ is a constant.

Different values for this constant have been used in literature. The value used in this work is 1226 .

The described model allows the study of the influence of soot on the temperature distribution in the flame, as it will be discussed in the next section. This model will be referred to as Case2.

\section{APPLICATION AND RESULTS}

As mentioned earlier in section "Flame studied and its structure", the studied flame is an axisymmetric coflow laminar ethylene/air nonpremixed flame below the smoke point. In order to evaluate the new submodel for soot, a modified conservation equation for soot mass fraction has been incorporated into FDS (DNS mode) by adding the new source terms for soot formation and oxidation as shown in Eq. 21:

$$
\frac{\partial\left(\rho Y_{s}\right)}{\partial t}+u \cdot \nabla \rho Y_{s}+\rho Y_{s} \nabla \cdot u=\dot{\omega}_{s f}^{\prime \prime \prime}-\dot{\omega}_{s, o x}^{\prime \prime \prime}
$$

The soot formation source term parameters are the following: $T_{a c}=2000 \mathrm{~K}$ and $\gamma=2.25 . A$ and $\xi_{\text {incep }}$ are numerically calibrated. The soot oxidation source term as explained earlier was taken as constant (around 3 $\mathrm{kg} / \mathrm{m}^{3} / \mathrm{s}$ ). This constant was estimated using Eq. 15 for a visible flame height, $L_{V H}$, which is $0.088 \mathrm{~m}$ [14]. The estimated stoichiometric height, $L_{s t}$, via FDS simulation was $0.077 \mathrm{~m}$. Besides the oxidation region was slightly extended from below the stoichiometric height (at a mixture fraction of 0.07 ) to the visible flame height where the mixture fraction is around 0.03 . This helps having a better profile for the centreline temperature (see further explanations). Thermophoretic effects have been neglected. The total amount of solid carbon that forms soot is assumed to be small enough not to interfere in the carbon balance [11]. Therefore, no sink term was introduced in the mixture fraction conservation equation. 
The calibration exercise was focused on capturing two main features of the experimental data: (1) the height (in the axis) at which soot starts appearing, and this is attributed to the value of $\xi_{\text {incep. }}$, and (2) the peak values of soot volume fraction, and this is mainly attributed to the value of the pre-exponential factor $A$ that gives the soot loading (which will subsequently differ from a fuel to an other). The values used in the presented simulation are: $A=4.1 \times 10^{-5}$ and $\xi_{\text {incep. }}=0.17$.

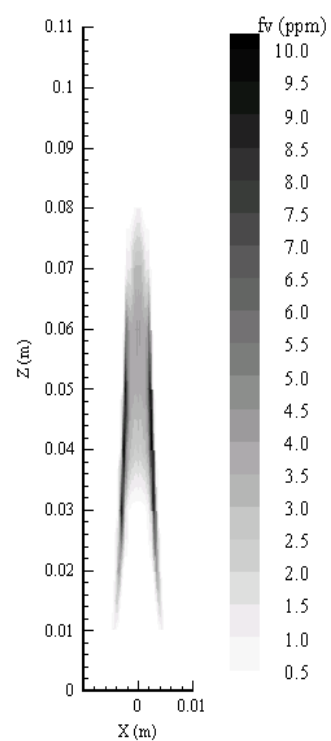

(a) Measurements of soot volume fractions

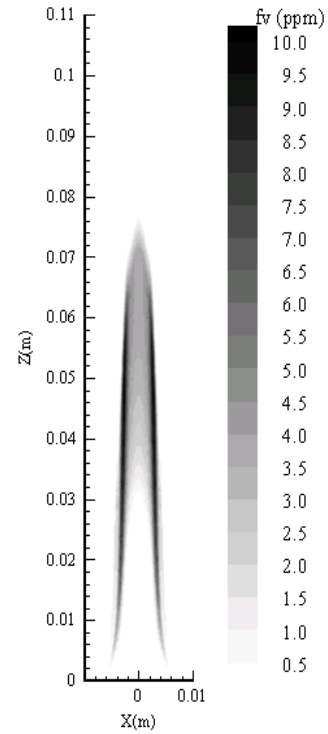

(b) Predicted soot volume fractions

Fig. 1. Comparison of the measured and predicted soot volume fraction distributions in the studied flame.

Figure 1 shows a very good qualitative and quantitative agreement in the overall shape of the soot volume fraction distribution in the studied flame. In fact, unlike the soot model based on the $\mathrm{C}_{2} \mathrm{H}_{2}$ growth mechanism and used by Liu et al. [15], the semi-empirical model proposed in this work reproduces well the amount of soot both in the centreline and in the wings where the peak (around $10 \mathrm{ppm}$ ) is reached.

Figure 2 shows a good agreement in the prediction of soot volume fraction in the radial direction at different heights above the burner for both radiation models. However, the soot absorption model shows better results in terms of location of the peak and decay of soot volume fraction after the peak is reached. The linear decay of soot in the centreline in the oxidation region (Fig. 3) is due to the constant oxidation rate. A temperature dependence of soot oxidation might improve the results.

Figure 4 shows that by using the second radiation model and therefore considering the influence of soot on the temperature field through radiant loss, a better agreement with the experiments is achieved. However, in both cases, an early decay of the temperature was observed in comparison with the experimental data. The same numerical result was observed by Said et al [11].

The distribution of the predicted temperature in the centreline of the flame is compared to the experimental data measured not exactly in the centre but at $0.25 \mathrm{~mm}$ (Fig. 5). The second model shows better agreement with the experiments. Besides, the same trend exhibited by the second model was numerically observed by Liu et al [15]. 

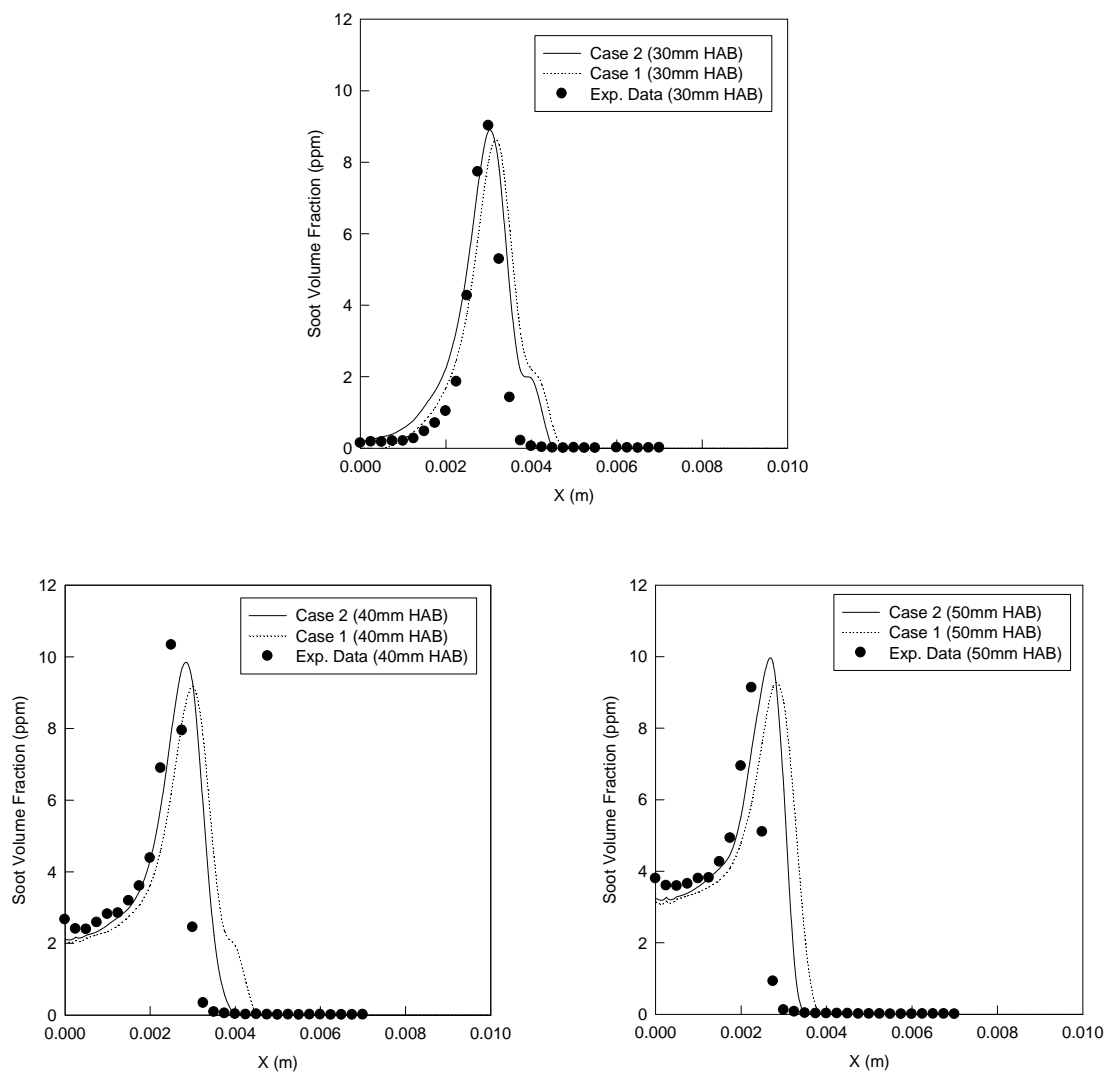

Fig. 2. Radial soot volume fraction profiles at different heights above the burner (HAB) for the studied flame (dashed line: case 1 prediction; full line: case 2 prediction; symbols: experiment).

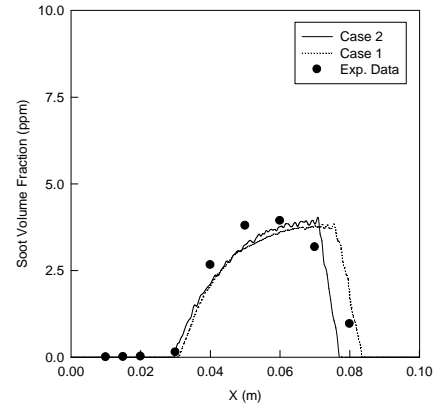

Fig. 3. Centreline soot volume fraction profiles for the studied flame (dashed line: case 1 prediction; full line: case 2 prediction; symbols: experiment). 

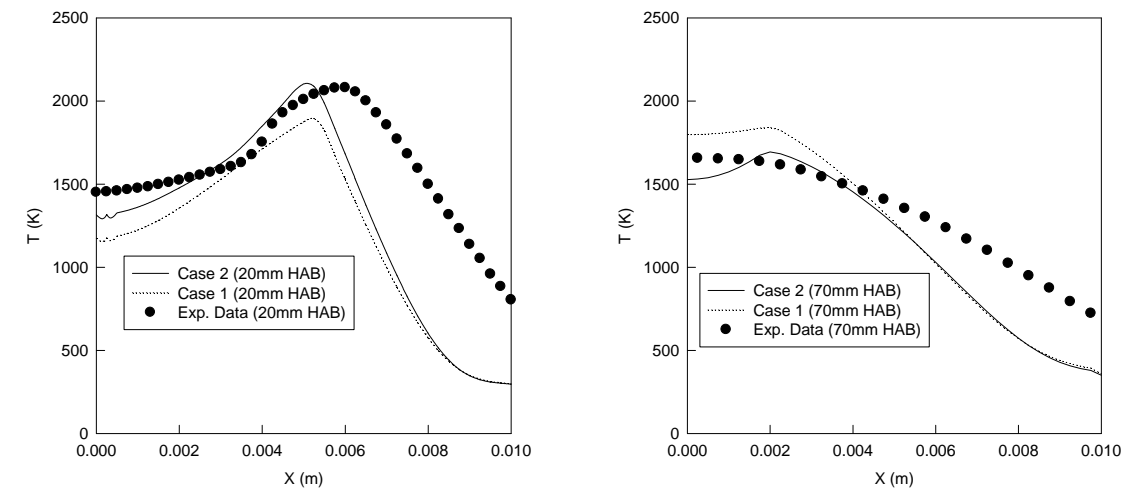

Fig. 4. Radial temperature profiles at two different heights above the burner (HAB) for the studied flame (dashed line: case 1 prediction; full line: case 2 prediction; symbols: experiment).

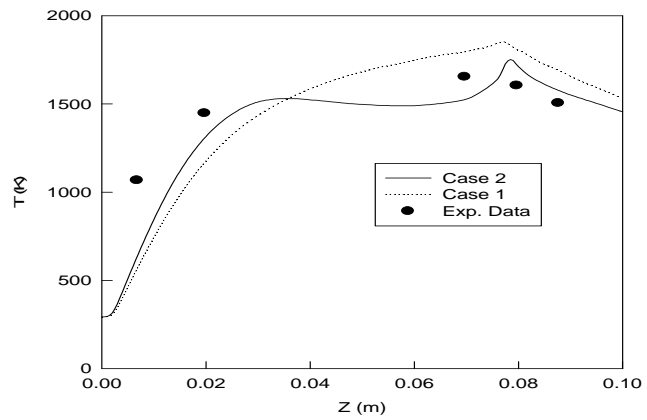

Fig. 5. Centreline temperature profiles for the studied flame (dashed line: case 1 prediction; full line: case 2 prediction; symbols: experiment).

\section{CONCLUSIONS AND PERSPECTIVES}

The soot model developed in this work for laminar non-premixed flames provides a good agreement with experimental data and observations. The theoretical assumptions and flow similarity relationships are well supported by numerical simulations. Contrary to the soot models based on the acetylene growth mechanism [15], the model predicts soot volume fraction in the centreline as well as in the wings.

The generalization of such a model to real fuels in fires with unknown chemistry seems more feasible in comparison to other semi-empirical models. This is made possible thanks to the simplicity of the model and also the experimental measurements on which it relies, e.g. the use of visible (luminous) flame height, stoichiometric flame height and soot concentration to estimate the oxidation rate. Consequently, the number of numerical calibrations is reduced. However, the results presented are highly compounded not only by experimental uncertainties in the soot volume fraction measurements but also the temperature field calculation that is highly influenced by radiation to which soot is the major contributor. Perspectives to this work will be hence, the evaluation of the model against data in other experimental configurations (e.g. the transition from non-smoking to smoking flames) as well as more detailed treatment of radiation and extension to other fuels through the smoke point concept. 


\section{REFERENCES}

[1] Kennedy, I.M., (1997) Models of soot formation and oxidation, Prog. Energy Combust. Sci. 23: 95-132, doi:10.1016/S0360-1285(97)00007-5

[2] Moss, J. B., Stewart, C. D., and Young, K. J., (1995) Modeling Soot Formation and Burnout in a High Temperature Laminar Diffusion Flame Burning under Oxygen-Enriched Conditions, Combust. Flame 101: 491-500, doi:10.1016/0010-2180(94)00233-I

[3] Lautenberger, C.W., de Ris, J., Dembsey, N.A., Barnett, J.R., and Baum, H.R., (2005) A simplified model for soot formation and oxidation in CFD simulation of non-premixed hydrocarbon flames, Fire Safety Journal 40: 141-176, doi:10.1016/j.firesaf.2004.10.002

[4] Lindstedt, P., A simple reaction mechanism for soot formation in non-premixed flames, Lee, R.S., Whitelaw, J.H., and Wung, T.S. (Eds), Aerthermodynamics in Combustors, Springer-Verlag, Berlin, Germany, 1992, p. 145-156.

[5] Delichatsios, M.A., (1994) A Phenomenological Model for Smoke-Point and Soot Formation in Laminar Flames, Combust. Sci. Technol. 100: 283-298, doi:10.1080/00102209408935457

[6] Burke, S.P., and Schumann, T.E.W., (1928) Diffusion flames, Industrial and Engineering Chemistry 20(10): 998-1004, doi:10.1021/ie50226a005

[7] Roper, F.G., Smith, C., (1979) Soot Escape from Laminar Air-Starved Hydrocarbon Flames, Combust. Flame 36:125-138, doi:10.1016/0010-2180(79)90055-5

[8] Sunderland, P.B., Mendelson, B.J., Yuan, Z.G., and Urban, D.L., (1999) Shapes of Buoyant and Nonbuoyant Laminar Jet Diffusion Flames, Combust. Flame 116:376-386, doi:10.1016/S0010$\underline{2180(98) 00045-5}$

[9] Kumfer, B.M., Skeen, S.A., Chen, R., and Axelbaum, R.L., (2006) Measurement and analysis of soot inception limits of oxygen-enriched coflow flames, Combust. Flame 147:233-242, doi:10.1016/j.combustflame.2006.08.004

[10] Du, J., and Axelbaum, R.L., (1995) The Effect of Flame Structure on Soot-Particle Inception in Diffusion Flames, Combust. Flame 100:367-375, doi:10.1016/0010-2180(94)00136-G

[11] Said, R., Garo, A., and Borghi, R. (1997) Soot Formation Modeling for Turbulent Flames, Combust. Flame 108:71-86, doi:10.1016/S0010-2180(96)00068-5

[12] Dobbins, R.A., Fletcher, R.A., and Chang, H.C., (1998) The Evolution of Soot Precursor Particles in a Diffusion Flame, Combust. Flame 115:285-298, doi:10.1016/S0010-2180(98)00010-8

[13] McGrattan, K.B., "Fire Dynamics Simulator (Version 4) Technical Reference Guide” National Institute of Standards and Technology Report NIST Special Publication 1018, Gaithersburg, MD, 2004.

[14] Smyth, K.C., available at $<\underline{\text { http://www..re.nist.gov/.re/.amedata/ }>\text {. }}$

[15] Liu, F., Guo, H., Smallwood, G.J., and Gülder, Ö.L., (2003) Numerical modelling of soot formation and oxidation in laminar coflow non-smoking and smoking ethylene diffusion flames, Combust. Theory Modelling 7 (2): 301-315, doi:10.1088/1364-7830/7/2/305

[16] Nagle, J., and Strickland-Constable, R.F., "Oxidation of carbon between $1000^{\circ} \mathrm{C}$ and $2000^{\circ} \mathrm{C}$ ”, Proceedings of the Fifth Carbon Conference, Pergamon, Oxford, 1962, p.154.

[17] Lee, K.B., Thring, M.W., and Beer, J.M., (1962) On the rate of combustion of soot in a laminar soot flame, Combust. Flame 6:137-145, doi:10.1016/0010-2180(62)90082-2

[18] Fenimore, C.P., and Jones, G.W., (1967) Oxidation of soot by hydroxyl radicals, J. Phys. Chem. 71:593-597, doi:10.1021/j100862a021 
[19] Kent, J.H., (1986) A Quantitative Relationship Between Soot Yield and Smoke Point Measurements, Combust. Flame 63:349-358, doi:10.1016/0010-2180(86)90004-0

[20] K.-C. Lin, G.M. Faeth, P.B. Sunderland, D.L.Urban, Z.-G.Yuan, (1999) Shapes of Nonbuoyant Round Luminous Hydrocarbon/Air Laminar Jet Diffusion Flames, Combust. Flame 116:415-431, doi:10.1016/S0010-2180(98)00100-X

[21] Liu, F., Guo, H., Smallwood, G.J., and Gülder, Ö.L. (2002) Effects of gas and soot radiation on soot formation in a coflow laminar ethylene diffusion flame, J. Quantit. Spec. Rad. Transfer 73:409-421, doi:10.1016/S0022-4073(01)00205-9

[22] Sivathanu, Y.R., and Gore, J.P., (1997) Effects of Gas-Band Radiation on Soot Kinetics in Laminar Methane / Air Diffusion Flames, Combust. Flame 110:256-263, doi:10.1016/S00102180(97)00065-5 